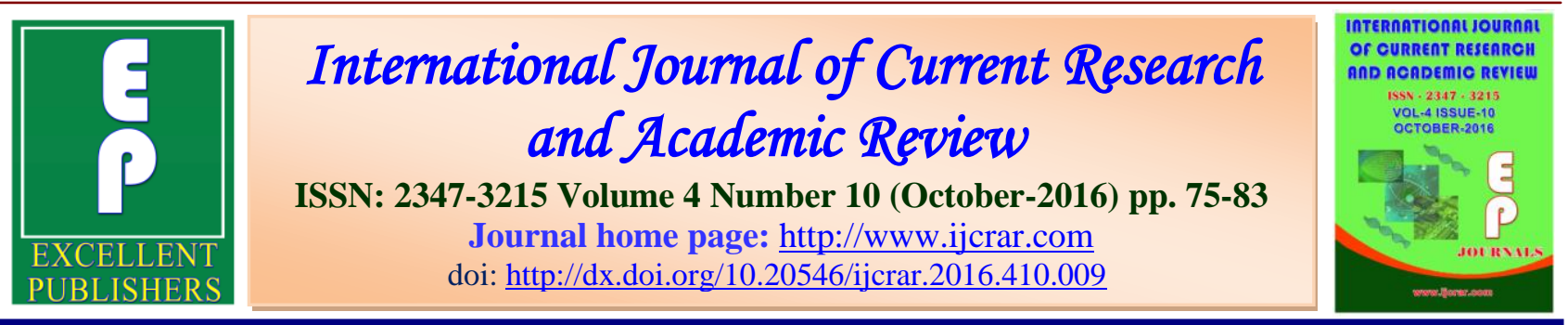

\title{
Biocompatibility of Thermoplastic Nylon Flexible Removable Partial Denture - A Review
}

\author{
FX Ady Soesetijo ${ }^{1 *}$, Dwi Prijatmoko ${ }^{2}$ and Lusi Hidajati ${ }^{3}$ \\ ${ }^{1}$ Department of Prosthodontics, Faculty of Dentistry, Jember University, Jember 68121- \\ Indonesia \\ ${ }^{2}$ Dental Hospital, Faculty of Dentistry, Jember University, Jember 68121 - Indonesia \\ ${ }^{3}$ Departement of Dental Materials, Faculty of Dentistry, Jember University, Jember 68121 - \\ Indonesia
}

*Corresponding author

KEYWORDS
Biocompatibility,
Denture,
Thermoplastic
nylon.

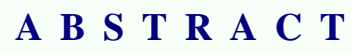

Thermoplastic nylon is an ideal choice for RPD base material construction. Biocompatibility of nylon resin was obtained from flexibility, elasticity and the absence of residue left behind during manipulation processes. The existing flexibility and elasticity were extremely enabling it to be placed on the undercut area around the tooth and gingival, hence it provided maximum retention and stabilization. The advantages of this plastic material include no hypersensitivity reactions and the absence of metal components as it in conventional denture, so that aesthetics purposes can be achieved. The disadvantages of this resin is the presence of the amide group of hydrophilic nylon resin that able to absorb water and further hydrolyzed by the salivary hydrolase enzymes. Therefore, it can affect the flexibility and it color stability. A flexible RPD, when properly designed, carefully made, and adjusted when needed can be an entirely satisfactory restoration. On the contrary, the presence of a flexible RPD may increase plaque formation around the remaining teeth, so oral hygiene should receive great emphasized. Finally, before and after constructing a partial removable prosthesis, patient is motivated to maintain his remaining dentition with good oral hygiene to preserve the integrity of the oral environment.

\section{Introduction}

Prosthetic dentistry materials offer several alternatives for restoring partial edentulous cases, such as removable partial denture (RPD), fixed bridges and dental implants.
RPD has become very popular since a few decades ago with the introduction of acrylic polymers and alloys ( $\mathrm{NiCr}$ and $\mathrm{CoCr}$ ). Currently, RPD is still the main choice, 
because of several considerations such as costs to physiological factors. Presently, more dentists recommend flexible denture because it has stronger, biocompatible, comfortable and relatively durable mechanical properties than acrylic resin.

The flexible material used today is the thermoplastic nylon or polyamide resin commonly found in the market as the Valplast, Flexiplast, Flexite, Pro-Flex, SunFlex, Lucitone, and DuraFlex, which is a mixture of synthetic materials between hexamethyl diamine and dibasic acid (Figure 1). The strong and flexible nature of the material is suitable for a wide range of oral environments, the design is simple, and it enables flexible nylon resin to act as a stress breaker and tissue conditioner (Yavutz and Aykent, 2012).

Conventional acrylic denture base causes greater stress on the supporting tissue when that compare to nylon base, leading to the bone's blood supply alteration as well as inflammation in mucoperiosteum. The above can lead to alveolar bone resorption and gingival resession (Bhola et al., 2010; Jorge et al., 2006).

Thermoplastic nylon has drawbacks, namely more difficult manipulation than the acrylic resin and has a tendency to absorb water, thus resulting in the dissolution of polymer chains that can affect the physical and mechanical properties. Moreover, thermoplastic resin is a protein derivative, where the influence of salivary hydrolase enzymes (protease and urease) can undergo protonation and hydrolysis, and eventually it will damage the polymer chain (Negrutiu et al., 2005).

Based on the above description, this article aims to examine the biocompatibility of flexible RPD from thermoplastic nylon material in the oral environment.

\section{Properties of Thermoplastic Nylon}

The properties of thermoplastic nylon denture base are: high water absorption; porosity caused by the entry of air during the injection molding; the elastic modulus of thermoplastic nylon is lower (111 MPa) than acrylic resin (348 $\mathrm{MPa})$, so it is flexible; high impact strength, so it does not easily fracture; better tensile strength than acrylic resin; linear shrinkage of 0.3 to $0.5 \%$, thus providing a real effect on the denture base adaptation; and surface hardness of 14.5 to 15.9 VHN is smaller when compared to acrylic resin (20 VHN); The ultimate tensile strength of nylon is 10,000-11,500 lb./sq. in. as compared with 7,000 - 8,000 ib./sq. in. for acrylic (Manappalil, 2003; Lai et al., 2003; Takabayashi, 2010).

\section{Advantages}

Flexible RPD is the optimal choice in cases where the patient does not want a fixed restoration, or the patient have no desire the existence of any metal element on their denture that will compromise their appearane (Figure 2). Several survey showed that patients wearing flexible denture were satisfied with their dentures, because it seems natural. In addition, the high standard function of flexible material, in terms of mastication, does not cause suffer from its supporting tissues.

The advantages of flexible RPD are: aesthetic is more acceptable in the absence of metal elements (figure 3); the material is elastic, thus the high chewable burden will be anticipated by the material flexibility; easy insertion, although on cases with undercut on the alveolar ridge; even in cases where the remaining natural teeth is tilted or tipped, the prosthesis can still be inserted only with slight adjustments; no tooth abutment modification, such as preparation of occlusal rest on the metal frame denture 
Int.J.Curr.Res.Aca.Rev.2016; 4(10): 75-83

(MFD) and conventional denture constructions; prosthesis can be previously immersed in hot water if necessary for the insertion purposes by utilizing the undercut area; and the simple construction without complicated preparation in the oral cavity (Negrutiu et al., 2005; Tandon et al., 2010).

\section{Disadvantages}

The disadvantages are: the plasticity of prosthesis-based material does not enable it to be thin like the metal frame; poor thermal conductor attributes the patient to feel less comfortable during consuming food and beverages; in patients with periodontal problem accompanied by wiggling on the remaining teeth will aggravate the situation if constructing a flexible prosthesis, because retention and stabilization utilize existing undercut; if there fractures or relining needs, it will be difficult to repair, because material manipulation must be done with special equipment that requires high temperatures and mold injection technique; and it is relatively more expensive compared to acrylic-based conventional denture (Thakral et al., 2012; Lowe, 2004; Kaira et al., 2012).

\section{Indications}

Flexible RPD is indicated in all cases which are also indicated for conventional denture, along with cases where conventional denture experience contraindications, such as a large undercut and allergic to acrylic resin and/or alloys. In patients who wear metal frames or conventional prosthesis, where the existence of clasp is aesthetically very disturbing, thus the flexible material becomes an alternative (Dharma and Shashidhara, 2014; DiTolla, 2004).

Patients having tilted teeth (due to missing adjacent tooth for long time) develop an undercut where rigid partial denture are tough to insert. In such case flexible partial denture are a better option (DiTolla, 2004).

It is also indicated in patients having microstomia, systemic diseases like scleroderma or due to any other reason if there is reduced mouth opening. In such case flexible RPD have shown a good success (Phoenix et al., 2004).

The following are other indications of flexible RPD applications: if cosmetic gingival layer is needed to compensate the supporting of lip and cheek muscles; patients with bruxism habit; in cases which require the construction of an unilateral space maintainer or unilateral RPD; and temporary prosthesis (Dharma and Shashidhara, 2014; DiTolla, 2004; Phoenix et al., 2004).

\section{Contraindications (DiTolla, 2004; Phoenix et al., 2004)}

Contraindications of flexible prosthesis occur, especially on patients who refused to have removable denture. In addition, the flexible RPD is not recommended for cases of a tremendous overbite $(>4 \mathrm{~mm})$, as it can cause the anterior teeth dislodgement in the antero-posterior movement. Flexible prosthesis is not indicated for cases where the few remaining natural teeth are with minimal undercut for retention requirement.

In the case of bilateral-free end with a knifeedge ridge shape accompanied by an enormous mandibular torus can cause unstable denture, because of the free end saddle of unsupported posterior areas, and the lack of denture bearing in the lingual area because it was blocked by the torus.

RPD from acrylic material offers ease in manufacturing compared to the metal frame, but both require tooth preparation accuracy to guide the placement of the occlusal rest as 
well as model surveying to facilitate the path of insertion. The main limitation of these materials lies in the existence of the clasp, which causes irritation of tooth abutment and the surrounding tissues, as well as the loss of aesthetic functionality (Lowe, 2004; Shamnur et al., 2005).

Acrylic resins and alloys have limitations, especially rigidity and aesthetic problems. The problem solution can be done by alternative thermoplastic nylon material. The key benefits of the material are its flexibility, so able to control the burden, and the design can be made without metal elements. Moreover, the dimensional stability of thermoplastic nylon is better than acrylic, due to the manipulation is done through injection moulding technique (Goiato et al., 2008).

Stress distribution of conventional RPD and MFD is controlled by the structural elements of the design, which mainly is the existence of the clasp (retentive arm, reciprocal arm and occlusal rest), minor connector and guiding plane. The rigid nature of the supporting tissue can be detrimental if the design is imprecise. While the flexible RPD is controlled by the material flexibility, so it acts as a stress breaker. Each area contained in the flexible base is independent, so there is no stress accumulation in certain areas (Prashanti et al., 2010).

Flexible prosthesis has the role as a tissue conditioner. Slight movements of the supporting tissue will stimulate blood circulation, and the transfer of occlusal forces are dynamic in the mucosa and alveolar bone beneath it, so it will reduce stress and prevent atrophy of supported tissue. Flexibility of major connector also prevents and eliminates the fulcrum changes. In rigid RPD, fulcrum should be compensated by designing retention, rest and passive retainer. The fulcrum role is very essential, because it indicates the instable direction of the denture (Parvizi et al., 2004).

Thermoplastic resin is more compatible than the alloy on MFD and acrylic resin. That is because the thermoplastic resin does not leave residue on time manipulation. Meanwhile, the acrylic resin has a residual monomer content in its manipulation process, which can cause allergic response or cytotoxic. MFD in the non-conducive oral environment will cause the corrosion of metal elements into saliva that can cause cytotoxicity, which is from free radical formation, DNA damage, and to cells death (Tandon et al., 2010; Al-Hiyasat and Darmani, 2005; Imirzalioglu et al., 2012).

In the case of free end denture, especially on the mandibular, denture construction with flexible materials will cause problems, because the necessary components are rigid to cope with the leverage. As with conventional denture, there is a clasp component that can hold the denture in place in order to avoid leverage. Therefore, flexible RPD should be applied to the bonded saddle cases. In general, the design of flexible denture is mucosa borne, where denture is supported by the underlying mucosa and alveolar bone. It has the disadvantage of lacking receptor neurons in the denture supporting area that then result in the absence of a warning or danger signals over enormous mastication forces, which in turn causes alveolar bone resorption.

Thermoplastic nylon takes form a long linear chain that responsible for its flexibility, but in the long-term usage with the hydrophilic nature and the influence of changes in salivary $\mathrm{pH}$ will lead to the breakdown of the polymer chains that can 
alter its physical nature. This can occur because of lack of the $\mathrm{C}=\mathrm{O}$ and $\mathrm{C}-\mathrm{N}$ bonds, which can easily form a hydrogen bridge by the effect of acid $\mathrm{pH}$ or polymer hydrolysis by salivary hydrolase enzymes. Unlike the acrylic resin composed of long and branched polymer, the breaking of polymer chains gives less effect on its physical nature. $\mathrm{C}=\mathrm{O}$ groups (chromophores) in the thermoplastic nylon are covalent of unsaturated group, which has a double bond, so it is very easily polarized. While $-\mathrm{N}-\mathrm{H}$ groups (auxochromes) are covalent saturated group, easily polarized when it is bind to free radicals and chromophores, thus causing discoloration (DiTolla, 2004; Shah et al., 2014).

Saliva contains cathions $\left(\mathrm{Na}^{+}, \mathrm{Ca}^{2+}, \mathrm{Mg}^{2+}\right.$, $\left.\mathrm{K}^{+}\right)$and anions $\left(\mathrm{H}_{2} \mathrm{PO}_{4}{ }^{-}, \mathrm{HPO}_{4}{ }^{2-}, \mathrm{Cl}^{-}, \mathrm{HCO}_{3}{ }^{-}\right.$ ), enzymes and bacteria. These ions can break the polyamide resin bond chain; can bind other molecules due to differences in electronegativity. Bacteria can metabolize and produce acids that cause the $\mathrm{pH}$ to drop. The decreasing $\mathrm{pH}$ causes the polymer chains protonization. Protonization occurs if $\mathrm{H}^{+}$binds to the $\mathrm{C}$ and $\mathrm{O}$ into $\mathrm{C}=\mathrm{OH} . \mathrm{O}$ atoms in the $\mathrm{OH}$ groups will be reactive because of the excess electron (Cole and Estoe, 1997; Nair et al., 2012).

In the case of immediate denture, the base material selection is very essential. Rigid acrylic denture base polymeric and the existence of clasp cause the supporting tissue to receive an overload and irritation. Whereas, if the elastic and flexible thermoplastic nylon is selected; thus the bandage, haemostatic, functional stimulation and stress breaker functions will remain intact. This is very advantageous because it will accelerate wound healing.
The oral hygiene of flexible denture wearing patient must be maintained, because amide groups $\left(-\mathrm{NH}_{2}\right)$ on thermoplastic nylon are hydrophilic, so it is easy to absorb water and are susceptible towards $\mathrm{pH}$ changes. This can cause the breakdown of polymer chains that have an impact on surface roughness. The condition is potential for opportunistic microorganism attachment, such as Candida albicans. Poor oral hygiene gives imbalance secretion of salivary proteins.

The role of saliva in the colonization of Candida albicans is still controversial. The saliva possesses defensive molecules as lyzozymes, lactoferine, calprotectin, Ig A that decrease the adhesion of Candida to the oral mucosa and denture base surfaces. In the other hand, salivary proteins as the mucines and the staterins may act as adhesion of Candida species (Daniluk et al., 2006; Salerno et al., 2011; Zeina et al., 2012).

Metal clasps are designed in such a way that they do not come into contact with the gingival margin, but the resin clasp of flexible denture covers the tooth structure of the cervical region of abutment teeth, the marginal gingiva, and the labial/buccal mucosa. As a wide area around the abutment teeth becomes unhygienic, this may cause or exacerbate caries and periodontal disease.

The need for adequate dental plaque control has been emphasize, and patients with poor oral hygiene and those who do not respond regular repeat appoinments are not suitable candidate. As the degradation of resin materials may also increase the adherence of dental plaque, worsening the cleanlines of denture, regular oral maintenance is essential. 


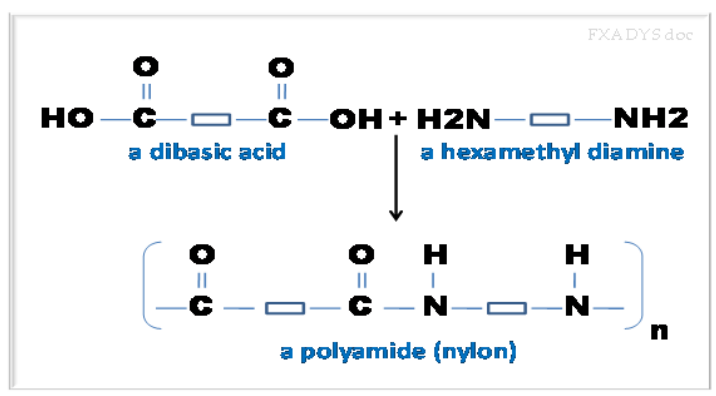

Figure 1. Chemical structure of thermoplastic nylon

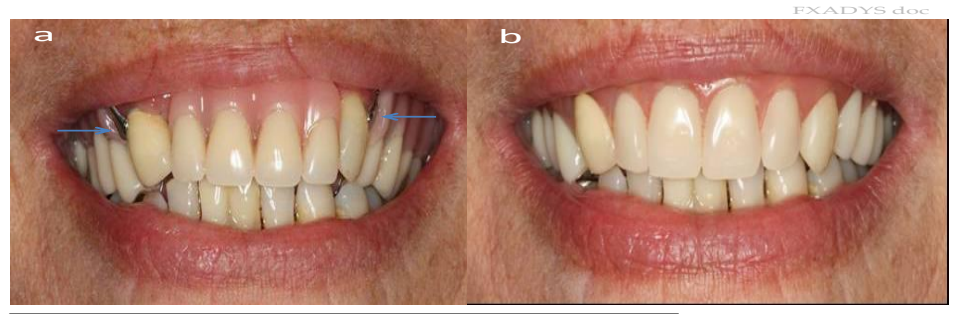

Figure 2. (Gomes et al, 2014)

a. Old conventional acrylic RPD with visible clasp

b. New thermoplastic nylon flexible RPD

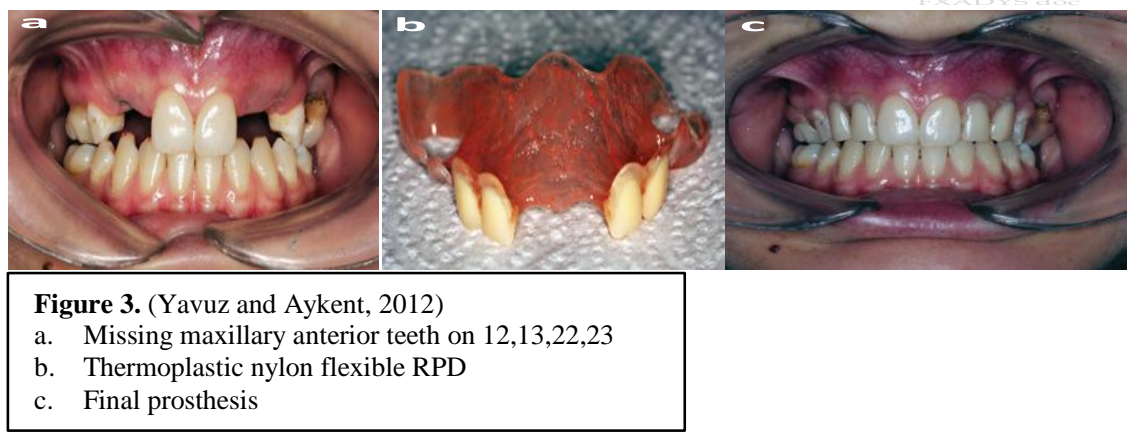

In patients who wear nylon denture base with no occlusal support, should the denture sink then the resin clasp compresses the marginal gingiva, potentially causing its mechanical damage. It has been reported that RPD with resin clasp structures at all tend to sink (Hosoi, 2009), suggesting that 
more carefully follow up is required for patients with resin clasp denture.

Flexible dentures exhibit viscoelastic behaviour that lead to improve masticatory functions and patients comfort compared with that of hard dentures. Flexible denture shows minimal effects on the mucosa of denture bearing areas. Furthermore, it is healthier because of the capability to produce fuctional stimulation in the stomatognathic system. It means that a maximum biocompatibility of the flexible prosthesis can be achieved (Mustafa et al., 2013).

A flexible RPD, when properly designed, carefully made, and adjusted when needed, can be an entirely satisfactory dental restoration and serve as a means of preserving the remaining oral structures as well as restoring missing dentition and good periodontal health to the remaining structure (Kulak et al., 2002). The presence of a RPD may increase plaque formation around the remaining teeth, so oral hygiene should be received greater emphasis in these patients. It can be expected that the denture will be preserved better and longer in the long term future (MacEntee et al., 1998; Carlson et al., 1993. Therefore, before and after constructing a partial removable prosthesis, patient should be motivated to maintain the remaining dentition by good oral hygiene lead to the preservation of the oral environment integrity (Bissada et al., 1994; Heath, 1993).

\section{Conclusion}

Complex oral conditions requires special attention in the denture construction. Flexible RPD made from thermoplastic nylon is an alternative solution for patients who have no desire the use of rigid denture and conventional RPD. Flexible prosthesis provides comfort to patients due to its elasticity, aesthetic, and biocompatibility. However, the presence of the $\mathrm{C}=\mathrm{O}$ and $\mathrm{C}=\mathrm{N}$ bonds, which are easily to form hydrogen bridge, as well as the hydrophilic $-\mathrm{NH}_{2}$ will be easily hydrolyzed by the salivary hydrolase enzymes, thus affecting the flexibility, odor and color stability.

Thermoplastic nylon flexible RPD is an invaluable restoration option to the patient providing the careful diagnosis and treatment planning concerning establishing periodontal health, achieving and maintaining excellent oral hygiene, optimal design and construction of the prosthesis regarding various components and occlusal scheme. The success of the treatment lies in the hands of the clinician who must be totally competent to render a comprehensive diagnosis of partially edentulous ridge and must plan every detail of treatment.

\section{References}

Al-Hiyasat, Darmani, H. 2005. The effects of recasting on the cytotoxicity of base metal alloy. J. Prosthet. Dent., 93(2): 158-163.

Bhola, R., Bhola, S.M., Liang H., Mishra B. 2010. Biocompatible denture polymers-A review. Trends Biomater. Artif. Organs, 23(3): 129-136.

Bissada, N., Ibrahim, S., Barsoum, W. 1994. Gingival responses to various type of removable partial dentures. J. Perio., 45: 651.

Carlson, G., Hedegard, B., Koivumma, K. 1993. Studies on partial denture prosthesis. IV. Final result of four years longitudinal investigation of dento-gingivally supported partial denture. Acta. Odont. Scant., 23: 433.

Cole, A.S., Estoe, J.E. 1997. Biochemistry and oral biology. J. Wright Publisher, New York, 161-170. 
Daniluk, T., Tokajuk, D., Stokowski, W., Fiderouk, K., Sciepuk, M., Zaremba, M.L. 2006. Occurrence rate of oral Candida albicans in denture wearer patients, Adv. Med. Sci., 51(1): 77-80.

Dharma, A., Shashidhara, H.S. 2014. A review: Flexible removable partial dentures. J. Dent. Med. Sci., 13(1): 5862.

DiTolla, M. 2004. Valplast: Flexible, esthetic partial denture. Chairside Perspect, 5(1): 1-4.

Goiato, M.C., Panzarini, S.R., Tomiko, C., Luvizuto, E.R. 2008. Temporary flexible immediate removable partial denture: a case report. Dent. Today, 27(3): 114 - 116.

Gomes, S.G.F., Del Bel Cury, A.A. 2014. Flexible resin an esthetic option for partially edentulous patients. Rev. Gauch. Odontol., 63(1): 81-86.

Heath, J.R., Boru, T.K, Grant, A.A. 1993. The stability of temporary prosthetic base materials. J. Oral Rehabil., 20(4): 363-372.

Hosoi, T. 2009. Non clasp denture. D. E., 168: 1-4.

Imirzalioglu, P., Alaaddinoglu, E., Yilmaz, Z., Oduncuoglu, B. 2012. Influence of recasting different type of dental alloy on gingival fibroblast cytotoxicity. $J$. Prosthet. Dent., 107(1): 24-33.

Jorge, J.H., Giampaolo, E.T., Vergani, C.E., Machado, A.L., Pavarna, A.C., Carlos, I.C. 2006. Effect of postpolymerization heat treatments on the cytotoxicity of two denture base acrylic resins. J. Appl. Oral Sci., 14(3): 203-207.

Kaira, L.S., Dayakara, H.R., Singh, H.R. 2012. Flexible denture for partial edentulous arches-a case report. $J$. Dentofac. Sci., 1(2): 39-42.

Kulak, O.Y., Kazazoglu, E., Arikan, A. 2002. Oral hygiene habits, denture cleanliness, presence of yeast and stomatitis in ederly people. J Oral Rehabil., 29(3): 300-304.

Lai, Y.L., Lin, H.F., Lee, S.Y. 2003. In vitro color stability, stain resistance, and water sorption of four removable gingival flange materials. J. Prosthet. Dent., 9(3): 293-300.

Lowe, L.G. 2004. Flexible denture flanges for patients exhibiting undercut tuberosities and reduced width of the buccal vestibule: a clinical report. $J$. Prosthet. Dent., 92(2): 128 - 131.

MacEntee, M.I., Glik, N., Stolar, E. 1998. Age, gender, dentures and oral mucosa disorders. Oral Dis., 4(1): 32-36.

Manappalil, J.J. 2003. Basic dental materials. Jaypee Brother Med. Publ., New Delhi, 2nd ed. 46-63.

Mustafa, G.M., Al Baki, M.A.A., Naji, S.A. 2013. Comparing the effect of denture base materials on hygiene of mucosal denture bearing area. Tikrit J. Dent. Sci., 3(1): 71-76.

Nair, A.S.U., Thavarajah, R., Ranganathan, K. 2012. Saliva and dental practice. $J$. Dr. NTR. Univ. Health Sci., 1: 72-76.

Negrutiu, M., Sinescu, C., Romano, M., Pop, D., Lakatus, S. 2005. Thermoplastic resin for flexible framework removable partial denture. Timisoara Med. J., 55(3): 295-299.

Parvizi, A., Lindquist, T., Schneider, R., Williamson, D., Boyer, D., Dawson, D.V. 2004. Comparison of the dimensional accuracy of injection molded denture base materials to that of conventional pressure-pack acrylic resin. J. Prosthodont., 13(2): 83-89.

Phoenix, R.D., Mansueto, M.A., Ackerman, N.A., Jones, R.E. 2004. Evaluation of mechanical and thermal properties of commonly used denture base resins. $J$. Prosthodont., 13(1): 17 - 27.

Prashanti, E., Jain, N., Shenoy, V.K., Reddy, J.M., Shetty, B.T., Skalanha, S. 2010. Flexible denture: A flexible 
option to threat edentulous patients. $J$. Nepal Dent. Assoc., 11(1): 85-87.

Salerno, C., Pascale, M., Contaldo, M., Esposito, V., Busciolano, M., Milillo, L. 2011. Candida assiciated denture stomatitis. J. Oral Med. Pathol., 16(2): 39-43.

Shah, J., Bulbule, N., Kulkarni, S., Shah, R., Kakade, D. 2014. Comparative evaluation of sorption, solubility and microhardness of heat cure polymethylmethacrylate denture base resin \& flexible denture base resin. $J$. Clin. Diagn. Res., 8(8): 1-4.

Shamnur, S.N., Jagadeesh, K.N., Kalavathi, S.D., Kashinath, K.R. 2005. "Flexible dentures"- an alternate for rigid dentures? J. Dent. Sci. Res., 1(1): 74 79.
Takabayashi, Y. 2010. Characteristic of denture thermoplastic resin for non clasp denture. Dent. Mater. J., 29(4): $353-361$.

Tandon, R., Gupta, S., Agarwai, S.K. 2010. Denture base materials : From past to future. J. Indian Dent. Sci., 2(2): 3339.

Thakral, G.K., Aeran, H., Yadav, B., Thakral, R. 2012. Flexible partial denture, a hope for the challenged mouth. People's J. Sci. Res., 5(2): 5559.

Yavuz, T., Aykent, F. 2012. Temporary flexible partial denture: A clinical report. Clin. Dent. Res., 36(2): 41-44.

Zeina, M.A., Eman, A.M., Inas, A.J. 2012. Adherence of candida albicans to flexible denture base materials. $\mathrm{Al}$ Rafidian Dent. J., 12(2): 229-235.

\section{How to cite this article:}

FX Ady Soesetijo, Dwi Prijatmoko and Lusi Hidajati. 2016. Biocompatibility of Thermoplastic Nylon Flexible Removable Partial Denture - A Review. Int.J.Curr.Res.Aca.Rev.4(10): 75-83. doi: http://dx.doi.org/10.20546/ijcrar.2016.410.009 